\title{
Docência com Portadores de Deficiência Visual no Curso Técnico em Informática
}

\author{
Jiani Cardoso da Roza, IFFarroupilha/Alegrete - jiani@al.iffarroupilha.edu.br \\ Marcelo Pedroso da Roza, IFFarroupilha/Alegrete - \\ mroza@al.iffarroupilha.edu.br \\ Heleno Carmo Borges Cabral, IFFarroupilha/Alegrete - hcabral@iffca.edu.br \\ Úrsula Adriane L. Fernandes Ribeiro, IFFarroupilha/São Borja - \\ ursularibeiro@sb.iffarroupilha.edu.br \\ João Carlos de C. e S. Ribeiro, IFFarroupilha/São Borja - \\ jribeiro2@gmail.com
}

\begin{abstract}
RESUMO
O objetivo deste trabalho é mostrar a experiência de ensino com alunos portadores de deficiência visual em uma turma do Curso Técnico em Informática do Instituto Federal Farroupilha - Campus Alegrete. Apresentar as oportunidades e limitações que surgem diariamente aos professores, os quais necessitam adaptar seu modo de ensino e preparar o material didático para atender a diversidade da classe, buscando meios para proporcionar uma adaptação de forma confortável aos alunos com o uso de ferramentas digitais de acessibilidade que o campus oferece.
\end{abstract}

Palavras-chave: deficiência visual, softwares leitores de tela, alunos cegos.

\section{Teaching with Visually Impaired Persons in the Course in Computer Technician}

\begin{abstract}
The aim of this study is the teaching experience with students with visual impairment in a group of Computer Technician Course at the Federal Institute Farroupilha - Campus Alegrete. Present the opportunities and limitations that arise daily to teachers who need to adapt their way of teaching and preparing teaching materials to meet the diversity of the class, looking for ways to provide a comfortable way of adapting to students using digital tools for accessibility that the campus offers.
\end{abstract}

Keywords: visual impairment, screen readers, blind students.

\section{Introdução}

Atualmente é possível encontrar no mercado diversos softwares que facilitam a inserção tecnológica de deficientes visuais. Entretanto, muitas dessas tecnologias somente são 
conhecidas pelas instituições de ensino a partir do momento que alunos com deficiência visual ingressam em seus colegiados e têm a sua disposição laboratórios de informática.

O campus Alegrete do Instituto Federal Farroupilha (IFFCA), possui um Núcleo de Atendimento aos Portadores de Necessidades Especiais (NAPNEs) desde o ano de dois mil e cinco, onde desempenha diversas ações voltadas a pessoas portadoras de necessidades especiais, em especial deficientes visuais, objeto deste estudo. A finalidade do núcleo é contribuir para a inclusão social utilizando-se de softwares para promover a sua inclusão e a acessibilidade da informática de forma simples e direta, ultrapassando assim esta barreira no aprendizado. O NAPNEs do IFFCA possui computadores com softwares especiais instalados para atender a este público, que recebe orientações e acompanhamento de docentes, técnicos e estagiários para a utilização dos programas disponíveis e na busca de outras tecnologias.

Através da convivência no campus e do trabalho do núcleo alguns jovens deficientes visuais têm ingressado nos diferentes cursos técnicos oferecidos pelo campus sendo que dois deles com ausência total de visão vislumbraram na informática perspectivas de desenvolvimento pessoal e profissional e matricularam-se no curso de Técnico em Informática do instituto em março de dois mil e nove (antiga Escola Agrotécnica Federal de Alegrete). Diante dos desafios a serem superados tanto pelos alunos deficientes visuais quanto por seus docentes ao longo do desenvolvimento de um curso técnico, este artigo busca apresentar as dificuldades encontradas e as iniciativas tomadas por seus docentes ao trabalhar com alunos cegos inseridos em turmas regulares, bem como a busca constante de softwares disponíveis para facilitar a aprendizagem destes alunos.

\section{Deficiência Visual}

Segundo Brasil (1994), citado por Caselli (2007), a necessidade visual, ou deficiência visual é compreendida como redução parcial ou total da visão, em sua capacidade de ver com o melhor olho, e após a melhor correção ótica. A partir de então e de acordo com Sonza (2003), as ferramentas computacionais abrem um espaço de oportunidades, "principalmente para as pessoas cujos padrões de aprendizagem não seguem os quadros típicos de desenvolvimento". Os estudos mostram que pessoas limitadas por deficiências não são menos desenvolvidas, mas se desenvolvem de forma diferente.

As pessoas com deficiência visual são classificadas em dois grupos principais: cegos e com visão parcial ou reduzida. Sendo que os dois grupos se enquadram no termo cegueira. A cegueira reúne indivíduos com vários graus de perda de visão, podendo ser a ausência total de visão até a perda da projeção de luz. Ela não significa, necessariamente, total incapacidade para ver, mas sim, prejuízo dessa capacidade (Silveira, 2007). Para a inserção tecnológica de pessoas com deficiência visual, vários softwares estão disponíveis no mercado brasileiro com soluções comerciais, gratuitas e educacionais. Cabe no entanto a instituição de ensino observar as características e particularidades de cada software para poder disponibilizar aos alunos que necessitam destas ferramentas. 


\section{Ferramentas de Acessibilidade Digital para Deficientes Visuais}

Leitores de tela segundo Amorim et al. (2009) são programas que, interagindo com o Sistema Operacional (SO) do computador, capturam toda e qualquer informação apresentada na forma de texto e a transforma em uma resposta falada utilizando um sintetizador de voz. Deste modo, o usuário (aluno) pode ouvir tudo o que está sendo mostrado, conforme navega pelo sistema e/ou utiliza os comandos do programa (IDV, 2010). Existem no mercado diversos softwares de acesso a deficientes visuais. Dentre os mais conhecidos e utilizados pelos cegos podemos citar: DOSVOX, Virtual Vision, NVDA, Jaws, Windows-eyes, Windows Bridge, Zoom-Text, e outros.

A seguir, serão apresentados resumidamente os três primeiros softwares citados por serem os programas disponíveis e em uso no IFFCA. Justifica-se a escolha destes por apresentarem melhor interação, facilidade de aprendizagem e recursos segundo a opinião dos próprios deficientes visuais que frequentaram os cursos oferecidos pelo NAPNEs da instituição.

- DOSVOX: O sistema operacional DOSVOX permite que pessoas com deficiência visual utilizem um microcomputador comum com uma placa de som para desempenhar uma série de tarefas, adquirindo assim um alto nível de independência no estudo e no trabalho. O DOSVOX vem sendo desenvolvido pelo Núcleo de Computação Eletrônica da Universidade Federal do Rio de Janeiro (UFRJ) que nos últimos anos vem se dedicando à criação de um sistema computacional destinado a atender os deficientes visuais. O DOSVOX é um sistema gratuito e está disponível na Internet (DOSVOX, 2009). No site do projeto, o usuário pode encontrar várias informações sobre o programa, textos técnicos, manuais, outros usuários e links para o download do programa. $\mathrm{O}$ DOSVOX possui versões para os sistemas operacionais Windows ${ }^{1}$ Vista, XP, NT e para o sistema operacional DOS, este último obsoleto atualmente. Uma das características desse sistema é que ele foi desenvolvido com tecnologia totalmente nacional, sendo o primeiro sistema comercial a sintetizar vocalmente textos genéricos na língua portuguesa (Sonza, 2003). Como o sistema lê e digitaliza o som em português, a interação é feita de forma simples e sem jargões. Este programa também utiliza padrões internacionais de computação podendo assim ser lido e ler dados e textos gerados por programas e sistemas de uso comum em informática (Silveira, 2007). O projeto DOSVOX possui um Centro de Assistência Educacional ao Cego responsável por fornecer suporte técnico aos usuários do sistema.

- Virtual Vision: O Virtual Vision foi desenvolvido em 1997 pela empresa MicroPower, de Ribeirão Preto. Segundo os desenvolvedores é o único software de leitura de telas desenvolvido nacionalmente capaz de funcionar sobre os aplicativos mais comuns utilizados na maior parte dos computadores (utiliza

\footnotetext{
${ }^{1}$ Windows Vista, XP, NT, DOS, Word, Excel, Internet Explorer, Outlook e MSN são marcas registradas da Microsot Corporation.
} 
sistema operacional Windows e reconhece Word, Excel, Internet Explorer, Outlook, MSN, Skype ${ }^{2}$, entre outros) (VVison, 2009). Como a maioria dos softwares comerciais o Virtual Vision disponibiliza uma versão de demonstração (Trial) e versões comerciais. A versão 6.0 foi lançada em 2008 e é distribuído gratuitamente pelo Banco Bradesco aos seus clientes e funcionários com problemas visuais. Características completas do Virtual Vision podem ser encontradas no site do programa no seguinte endereço eletrônico: http://www.virtualvision.com.br.

- NVDA: O NonVisual Desktop Access (NVDA) é um leitor de telas para o sistema operacional Windows é de distribuição livre (free) e de código aberto. $\mathrm{O}$ NVDA suporta os sintetizadores de voz compatíveis e usa uma estrutura modular, que permite suportar outros sintetizadores de voz que sejam programados. O NVDA vem sendo desenvolvido por Michael Curran (Melo, 2010) que juntamente com seus amigos fundou a NV Access (acesso não visual), uma organização não governamental sem fins lucrativos, destinada a desenvolver projetos e tecnologias livres que facilitem a acessibilidade para pessoas cegas e de baixa visão (NVDA, 2009). Além de funcionar com os aplicativos básicos do Windows 2000, XP e 2003 (WordPad, bloco de Notas, Microsoft Word e Excel, Outlook Express e Internet Explorer) o NVDA tem extensões para o Mozilla Firefox ${ }^{3} 2.0$ e superiores, sendo este o browser recomendado para se obter maior acessibilidade (Silveira, 2007). Também fornece suporte a aplicações desenvolvidas em Java e reconhece arquivos com extensão .pdf do Acrobat Reader ${ }^{4}$. Uma das vantagens desta ferramenta é oferecer uma versão portável que roda a partir de um dispositivo de armazenamento secundário ( $\mathrm{cd}, \mathrm{dvd}$, pen drive, etc.). Atualmente a ferramenta oferece internacionalização para mais de vinte (20) linguagens incluindo suporte ao português do Brasil.

Outras ferramentas podem ser encontradas para promover o acesso de pessoas com deficiência visual, porém os softwares citados são os mais utilizados pelos usuários atualmente portadores de tal deficiência. Normalmente a aprendizagem destes softwares no IFFCA é promovida pelo NAPNEs, juntamente com os docentes de sua área específica. Ao ingressarem nos cursos de nível técnico os deficientes visuais já possuem o domínio ou uma grande familiaridade com estas ferramentas. Informações mais completas incluindo análise de algumas ferramentas citadas podem ser encontradas nos trabalhos referenciados por Silveira (2007) e Sonza (2003).

\section{Deficientes Visuais no Ensino Técnico}

\footnotetext{
${ }^{2}$ Skype é marca registrada da Skype Limited.

${ }^{3}$ Mozilla Firefox é marca registrada da Mozilla Corporation.

${ }^{4}$ Acrobat Reader é marca registrada da Adobe Systems Incorporated.
} 
Há alguns anos o instituto oferece cursos de iniciação à informática para pessoas com deficiência visual. Neste curso os portadores de necessidades especiais (PNEs) além de conhecer os comandos básicos de um sistema operacional e alguns aplicativos como editores de texto, também aprendem a utilizar tecnologias de softwares existentes que proporcionam a sua inclusão ao meio digital.

A partir da criação do NAPNEs no IFFCA foram adquiridos os softwares Virtual Vision juntamente com os softwares free DOSVOX, NVDA e Linux Vox. Estando estes disponíveis nos laboratórios de informática do instituto para serem utilizados pelos alunos com esta deficiência durante as aulas e/ou sessões de estudo. Sendo todos estes softwares leitores de tela, cabe ao aluno escolher o de sua preferência. Além dos softwares para possibilitar a leitura do material didático, também foi adquirida pelo instituto uma impressora em Braille.

Devido alguns símbolos não poderem ser traduzidos diretamente para o braile, a impressão requer um planejamento do material didático voltado para a este tipo de impressão, tendo-se o cuidado de facilitar a leitura, evitando-se assim barreiras no aprendizado. Durante todos esses anos o principal objetivo do NAPNEs do IFFCA é o de trabalhar para a inserção social dos PNEs. Dentro da instituição estes alunos sentiram-se e sentem-se motivados a ingressar nos cursos técnicos oferecidos pelo campus. E desta forma, o trabalho desse núcleo foi ampliado visando a inclusão e a integração desses deficientes visuais à sala de aula dos cursos regulares oferecidos. Esses dois alunos anteriormente citados neste artigo, ingressaram no Curso Técnico em Informática na modalidade subsequente diurno e passaram por uma adaptação juntamente com a sua turma, a qual foi extremamente fácil e positiva suas inserções, pois todos os colegas foram sempre solidários aos novos colegas, sendo percebida pelos professores uma maior união dessa turma. Por outro lado, a dificuldade maior de adaptação ficou por parte dos professores que tiveram que rever sua prática de ensino de forma a acomodar estes alunos nas aulas do respectivo curso.

\subsection{Buscando por experiências semelhantes}

O trabalho realizado pelo NAPNEs da instituição é muito importante para preparar os alunos com deficiência visual a utilizar os softwares no ambiente da sala de aula. Também é importante para auxiliar os docentes na forma de proceder com esses alunos no dia a dia. Porém, os professores cientes das dificuldades que encontrariam, devido a falta de experiência para trabalhar em sala de aula com esse grupo de alunos, buscaram instituições de ensino técnico na região sul que tivessem um histórico de experiência com portadores de deficiência visual e que assim pudessem auxiliar os docentes do Curso Técnico de Informática do IFFCA.

Uma das iniciativas dos professores foi realizar uma visita ao Centro de Educação Tecnológica (CEFET) de Bento Gonçalves (atualmente Instituto Federal do Rio Grande do Sul) antes do início das aulas, a fim de buscar subsídios para o auxílio em suas respectivas disciplinas. Na rede de ensino público técnico federal o CEFET de Bento Gonçalves, no Rio Grande do Sul, é referencia na área de atendimento a alunos com necessidades especiais. O CEFET de Bento Gonçalves possuía um Núcleo de Atendimento aos Portadores de Necessidades Especiais (NAPNE) com o objetivo de promover a inclusão social, autonomia e preparação desses sujeitos para o mercado de 
trabalho que segundo Silva (2009) as empresas buscam pessoas qualificadas e que atualmente devido a Lei de inclusão, existem muitas vagas e faltam pessoas que preencham tais requisitos de qualificação profissional.

Criado em dezembro de 2004, este núcleo vem desenvolvendo atividades que propiciam a inclusão de pessoas com necessidades educacionais especiais (PNEEs), tais como: cursos de informática, teatro, atividades físicas, olericultura, atendimento psicológico, livro falado e digitação de material didático (RENAPI, 2004).

Partindo do conhecimento deste trabalho realizado em Bento Gonçalves três docentes do Curso Técnico em Informática do IFFCA foram a este centro vivenciar o trabalho do NAPNE e identificar soluções que pudessem ser adotadas em Alegrete para facilitar o ensino e a aprendizagem dos deficientes visuais. Nessa oportunidade, os visitantes puderam verificar os softwares utilizados pelo NAPNE e interagir diretamente com alguns alunos cegos que frequentam cursos técnicos naquele centro educacional. Os visitantes consideraram a visita extremamente produtiva, pois conseguiram compreender melhor como os alunos com tal deficiência podem tirar melhor proveito das aulas.

\subsection{Os desafios da sala de aula}

Ao serem inseridos alunos com cegueira total em salas de aulas regulares é perceptível um ritmo mais lento no desenvolvimento das aulas, pois embora os alunos cegos tenham o auxílio de softwares especiais, em várias situações a utilização dos mesmos é impraticável, como no caso de aulas práticas, sendo desta forma, a necessidade de uma maior atenção que a classe precisa dispensar a estes alunos, para que os mesmos possam acompanhar as atividades que estão sendo desenvolvidas.

O Curso de Técnico em Informática possui várias disciplinas de cunho teóricoprático, onde as práticas são realizadas no computador através diferentes programas e linguagens de programação. As disciplinas de cunho teórico tais como Empreendedorismo, Inglês, Português, entre outras, normalmente não apresentam problema de aprendizado para os alunos com deficiências visuais, pois as ferramentas utilizadas como, por exemplo, os leitores de tela juntamente com as explanações dos professores durante as aulas permitem um aprendizado significativo por parte desses alunos. Ressalta-se ainda, que os textos precisam ser preparados para os leitores de telas, visto que o leitor não reconhece algumas situações, tais como: "se um texto está em duas colunas", o programa não avisa ao ouvinte que acabou uma coluna e começou a outra, a não ser que esta informação esteja incorporada ao texto, outro fator importante é que as figuras também não são reconhecidas por esses leitores, sendo necessária uma descrição de cada figura antes de sua utilização no texto, bem como a utilização de legendas autoexplicativas.

\subsection{Material didático}

A preparação de material didático para ser lido por programas leitores de tela implica conhecimento dos professores das ferramentas utilizadas pelos deficientes visuais. Conhecendo as limitações dos programas os professores sabem o que é e o que não é possível disponibilizar nos materiais e a forma como devem ser disponibilizados. 
Muitas vezes é necessário produzir materiais diferentes para a turma de forma a tornar o material atrativo aos demais alunos. Como o curso técnico em informática possui docentes com facilidade no domínio de tecnologias computacionais a aprendizagem dessas ferramentas é rápida. Além do caráter prático do próprio curso o lema do IFFCA é "Aprender a fazer, fazendo". Assim, nas disciplinas de cunho teóricas-práticas, tais como Rede de Computadores, Hardware, Multimídia, Banco de Dados, etc. algumas adaptações tiveram que ser realizadas. A disciplina de redes de computadores tem suas aulas divididas em trinta por cento $(30 \%)$ teóricas e setenta por cento $(70 \%)$ práticas.

Nas aulas práticas os professores do curso encontraram dificuldades levando-os a algumas interrogações iniciais: "Como uma pessoa com deficiência visual vai fazer um cabo de rede se o padrão para sua confecção é por cores? Como esse aluno vai saber se fez certo se o testador de cabos não tem uma forma de avisar se o cabo ficou bem?" ou "como encaixar os conectores de áudio e dispositivos frontais USB no gabinete se estes conectores também são indicados por cores e letras em seus conectores”, etc.

$\mathrm{Na}$ tentativa de solucionar alguns problemas nesta área um dos professores do curso entrou em contato com o fabricante de cabos de rede para verificar a existência de algum tipo de cabo de rede texturizado que permitisse a identificação das cores pelo tato. Em resposta a essa solicitação foi recebida a informação que não seria possível atender a este tipo de público, pois além dele ser um público reduzido, o custo de produzir cabos com textura tornaria o produto não-comercial. Em resumo, não interessaria a indústria de cabos de redes produzirem cabos com esta especificação. A solução encontrada momentaneamente foi solicitar aos alunos com deficiência visual para decorar os padrões e com o auxilio de colegas e professores verificar se o padrão fora obedecido.

Também foi realizada uma pesquisa de mercado, através de contato via telefone e e-mail com alguns fabricantes, para verificar a existência de testadores de cabos que emitissem algum tipo de sinal sonoro quando algum cabo fosse testado, que pudesse ser utilizado pelos alunos com deficiência visual. Infelizmente, também não foram encontradas soluções comerciais para a situação. Por outro lado, a inexistência de testadores de cabos sonoros foi motivadora para o desenvolvimento de um trabalho de conclusão de curso de um grupo de alunos com a orientação de professores de hardware com conhecimentos de eletrônica. As dificuldades encontradas nas disciplinas de hardware que compreendem a montagem e manutenção de computadores foram supridas pelo tato. Ou seja, os alunos cegos precisavam decorar as posições dos componentes na placa mãe do computador a partir do toque, sendo informado a ele anteriormente o fabricante da placa mãe, uma vez que cada fabricante tem posicionamento diferente dos componentes na confecção de suas placas e também quais os componentes que estão a sua disposição para a montagem. Após a montagem da máquina, ou parte dela, um professor verifica se a prática está correta. Durante a montagem alguns colegas também auxiliavam o mesmo.

Nesta etapa, os primeiros alunos cegos concluíram com êxito as atividades nas suas respectivas disciplinas oferecidas no curso Técnico em Informática, tendo assim pleno êxito esta experiência. Como o Instituto só teve estes dois alunos com este tipo de deficiência, ainda é muito cedo para uma avaliação precisa que possa mostrar se os métodos adotados até o momento são adequados, pois a literatura nacional não revela 
experiências semelhantes com alunos cegos em cursos técnicos de informática. Certamente, novos obstáculos continuarão a se apresentar, pois várias outras disciplinas práticas que fazem parte do currículo, sendo estas as mais desafiadoras para os professores e seus alunos com deficiência visual, porém conviver com a diferença leva toda a turma ao crescimento e demonstra o grande potencial e motivação apresentados pelos alunos este tipo de deficiência.

\section{Considerações Finais}

O computador é atualmente uma ferramenta muito poderosa e que muito pode contribuir para a inclusão social de deficientes visuais. Vários softwares estão disponíveis atualmente auxiliando a inclusão não apenas digital destas pessoas, mas também a inclusão social dos mesmos. Geralmente, deficientes visuais não encontram dificuldades em lidar com as ferramentas de acessibilidade digitais disponíveis e inclusive são encorajados a ingressar em curso técnico por terem a sua disposição tais softwares que facilitam o seu dia a dia escolar e o acompanhamento do material didático disponibilizado.

O uso do computador amplia os horizontes de pessoas com necessidades especiais, pois permite a elas trabalhar, interagir e se divertir aumentando sua autoestima. Porém, alguns obstáculos são encontrados quando alunos com cegueira ingressam em cursos técnicos de informática, onde a prática de hardware e redes de computadores é facilitada pelo uso de cores em cabos e componentes e pelas constantes mudanças tecnológicas nestes componentes. Algumas disciplinas também se utilizam de programas específicos que exigem a manipulação dos elementos na tela. Neste caso, os softwares leitores de tela são pouco proveitosos. Desta forma, é necessário o estudo de estratégias de ensino que permitem a aprendizagem deste grupo e ao mesmo tempo dos demais alunos.

Os professores do IFFCA têm buscado constantemente conhecer iniciativas, experiências e softwares que busquem atender a este público permitindo aos mesmos a continuação dos estudos e uma formação técnica de qualidade.

\section{Referências Bibliográficas}

AMORIM, E. M.; Carvalho, J. L.; Menezes, L. K. B. Educação de Cegos Mediada pela Tecnologia. Secretaria de Educação de Salvador. Salvador, 2009. Disponível em: <http://www.smec.salvador.ba.gov.br/educacaodecegosmediadapelas tecnologias.pdf $>$. Acessado em: 16 out. 2010.

CASELli, B. C. A. Acesso à Informação Digital por Portadores de Necessidades Especiais Visuais: estudo de caso do Telecentro Acessível de Taguatinga, no Distrito Federal. Brasília: PPGCI/UNB, 2007. Dissertação de Mestrado. 
DOSVOX. Projeto DOSVOX. Apresenta link para downloads das versões do DOSVOX para sistemas operacionais da Microsoft. Disponível em: <http://intervox.nce.ufrj.br/dosvox/download.htm>. Acesso em: 24 fev. 2009.

IDV. Informática para Deficientes Visuais. Fundação Bradesco. Apresenta textos sobre as ações comunitárias e material didático para cegos. Disponível em: $<$ http://www.fb.org.br/Institucional/AcoesComunitarias/InformaticaparaDeficientes $>$. Acesso em 14 out. 2010.

MELO, R. Os 5 Principais Leitores de Telas para seu Computador. Revista Eletrônica Movimento Livre, set. 2010. Disponível em: <http://www.movimento livre.org/ informatica/ post-info.php?id=50>. Acesso em 17 out. 2010.

NVDA. NonVisual Desktop Access. Apresenta textos e softwares sobre acessos aos sistema e aplicativos Microsoft. Disponível em: < http://www.nvda-project.org>. Acesso em: 24 fev. 2009.

RENAPI. Projeto de Acessibilidade Virtual. Desenvolvido pelo Instituto Federal Rio Grande do Sul - campus Bento Gonçalves. 2004-2010. Apresenta textos, experiências e informações sobre o projeto. Disponível em: <http://bento.ifrs.edu.br/ acessibilidade>. Acesso em: 11 out. 2010.

SILVA, A. C. V. As Empresas e os Portadores de Necessidades Especiais. Revista Eletrônica Administradores: O Portal da Administração, out. 2009. Disponível em: $\quad<\mathrm{http}: / / \mathrm{www}$.administradores.com.br/informe-se/artigos/as-empresas-e-osportadores-de-necessidades-especiais/34777>. Acesso em 14 out. 2010.

SILVEIRA, C.; Reidrich, R.; Bassani, P. B. S. Avaliação das tecnologias de softwares existentes para a inclusão digital de dEficientes visuais através da utilização de requisitos de qualidade. IX Ciclo de Palestras sobre Novas Tecnologias na Educação. Cinted/UFRGS. Porto Alegre, v. 5, n. 1, Jul. 2007.

SONZA, A. P.; Santarosa, L. M. C. Ambientes digitais virtuais: acessibilidade aos deficientes visuais. Revista Novas Tecnologias na Educação. Cinted/UFRGS. Porto Alegre, v. 1, n. 1, Fev. 2003.

VVision. Virtual Vision - Inclusão digital para deficientes visuais. Apresenta soluções incluindo um software para leitura de telas. Disponível em $<$ http://www.virtualvision.com.br>. Acesso em: 24 fev. 2009. 